\title{
Review \\ Physiology in medicine: importance of hypoxic pulmonary vasoconstriction in maintaining arterial oxygenation during acute respiratory failure
}

\author{
Robert Naeije* and Serge Brimioulle ${ }^{\dagger}$ \\ *Department of Physiology, Erasme Campus of the Free University of Brussels, Belgium \\ tDepartment of Intensive Care, Erasme Hospital, Free University of Brussels, Belgium
}

Correspondence: R Naeije, MD, PhD, Department of Physiology CP 604, Erasme Campus CP 604, 808 Lennik Road, B-1070 Brussels, Belgium. Tel: +32 2 5553322; fax: +32 2 5554124; e-mail: rnaeije@ulb.ac.be

Received: 18 February 2001

Accepted: 19 February 2001

Published: 6 March 2001
Critical Care 2001, 5:67-71

(C) 2001 BioMed Central Ltd

(Print ISSN 1364-8535; Online ISSN 1466-609X)

\begin{abstract}
Hypoxic pulmonary vasoconstriction continues to attract interest more than half a century after its original report because of persistent mystery about its biochemical mechanism and its exact physiological function. Recent work suggests an important role for pulmonary arteriolar smooth muscle cell oxygen-sensitive voltage-dependent potassium channels. Inhibition of these channels by decreased $\mathrm{PO}_{2}$ inhibits outward potassium current, causing membrane depolarization, and calcium entry through voltage-dependent calcium channels. Endothelium-derived vasoconstricting and vasodilating mediators modulate this intrinsic smooth muscle cell reactivity to hypoxia. However, refined modeling of hypoxic pulmonary vasoconstriction operating as a feedback mechanism in inhomogeneous lungs, using more realistic stimulus-response curves and confronted with direct measurements of regional blood flow distribution, shows a more effective than previously assessed ability of this remarkable intrapulmonary reflex to improve gas exchange and arterial oxygenation. Further studies could show clinical benefit of pharmacological manipulation of hypoxic pulmonary vasoconstriction, in circumstances of life-threatening hypoxemia.
\end{abstract}

Keywords: acute respiratory failure, feedback, hypoxia, hypoxic pulmonary vasoconstriction, vascular smooth muscle cells

\section{What is hypoxic pulmonary vasoconstriction?}

Pulmonary hypertension as a result of asphyxia has been observed since the beginning of this century, but the first convincing evidence of hypoxic pulmonary vasoconstriction (HPV) together with a still valid functional interpretation was reported by von Euler and Liljestrand in 1946 [1]. These authors ventilated anesthetized cats with either hypoxic (fraction of inspired $\mathrm{O}_{2}\left[\mathrm{FIO}_{2}\right], 0.1$ ) or hypercapnic (fraction of inspired $\mathrm{CO}_{2}$, up to $19.6 \%$ ) gas mixtures, and found that both interventions increased pulmonary artery pressure $(\mathrm{Ppa})$ without change in left atrial pressure. Hypoxia increased Ppa proportionally more than hypercapnia in these experiments. Pulmonary blood flow $(Q)$ was not measured, and the possible explanation that at least part of the changes in Ppa could have been caused by hypoxia-induced or hypercapnia-induced increases in cardiac output was not taken into consideration. In the discussion of their results, the authors noted that "... oxygen

ARDS = acute respiratory distress syndrome; COPD = chronic obstructive pulmonary disease; $\mathrm{FlO}_{2}=$ fraction of inspired $\mathrm{O}_{2} ; \mathrm{Gfb}=$ gain due to feedback; $\mathrm{HPV}=$ hypoxic pulmonary vasoconstriction; $\mathrm{NO}=$ nitric oxide; $\mathrm{PAO}_{2}=$ alveolar $\mathrm{PO}_{2} ; \mathrm{Ppa}=$ pulmonary artery pressure; $\mathrm{PVR}=$ pulmonary vascular resistance; $\mathrm{VA}=$ alveolar ventilation. 
want and carbon dioxide accumulation have exactly the reverse effects on the systemic and pulmonary circulations respectively; in both cases, however, they seem to be adapted for their special purposes. They cause a dilatation of the vessels in the working organs which need a greater blood supply than during rest, but they call for a contraction of the lung vessels, thereby increasing the blood flow to better aerated lung areas, which leads to improved conditions for the utilization of alveolar air" [1].

According to this view, in lung parenchyma, local $\mathrm{PO}_{2}$ is determined by a ratio between oxygen delivery to the lungs, or alveolar ventilation (VA), and oxygen delivery from the lungs to the systemic tissues, or perfusion $(Q)$ :

$$
\mathrm{PO}_{2}=\mathrm{VA} / \mathrm{Q}
$$

In systemic tissues, however, local $\mathrm{PO}_{2}$ is determined by a ratio between oxygen delivery to the tissues, or perfusion $(Q)$, and local oxygen consumption $\left(\mathrm{VO}_{2}\right)$ :

$$
\mathrm{PO}_{2}=\mathrm{Q} / \mathrm{VO}_{2}
$$

It has now been better appreciated that alveolar hypoxia indeed increases the gradient between Ppa and left atrial pressure independently of associated changes in cardiac output, thus increasing pulmonary vascular resistance (PVR), but that $\mathrm{CO}_{2}$ has two opposing actions on pulmonary vascular tone. These actions are a direct relaxing effect and a constricting effect mediated by a decrease in $\mathrm{pH}$ [2].

Fifty years after the initial report of von Euler and Liljestrand, the basic attributes of HPV can be summarized as follows [3-5]. HPV occurs within seconds of the onset of alveolar hypoxia. HPV can be observed in isolated perfused lungs, pulmonary artery rings denuded of endothelium, and in single pulmonary artery smooth muscle cells. HPV seems to decrease with age, and exhibits marked interspecies and interindividual differences. The magnitude of $\mathrm{HPV}$ in vivo is inversely proportional to lung segment size. The main determinant of HPV is alveolar $\mathrm{PO}_{2}\left(\mathrm{PAO}_{2}\right)$, but mixed venous $\mathrm{PO}_{2}$ contributes to approximately one fifth of the response. HPV is inhibited by a variety of mediators present in the blood or released from lung parenchyma, such as substance $P$, calcitonine gene-related peptide, and atrial natriuretic peptides, by endothelium-derived vasodilators such as prostacyclin and nitric oxide (NO), by $\alpha$ adrenergic blockade, by $\beta$-adrenergic stimulation, by increased left atrial pressure, by increased alveolar pressure, by alkalosis, and by peripheral chemoreceptor stimulation. HPV is enhanced by acidosis, by $\alpha \beta$-adrenergic blockade, by epidural blockade, by low-dose serotonin, and by the inhibition of cyclooxygenase (aspirin, indomethacin) or NO synthase (L-arginine analogs). These latter two effects indicate that HPV is attenuated acutely by endogenous NO and prostacyclin. HPV can be inhibited by a series of vasodilating drugs including calcium channel blockers and halogenated anesthetics, and can be enhanced by the peripheral chemoreceptor stimulant almitrine and the appetite suppressant fenfluramines.

Hypoxic vasoconstriction mainly occurs in small precapillary arterioles [3-5] but small pulmonary veins also constrict in response to hypoxia, although not to more than 20\% of the total change in PVR [6]. An exaggerated hypoxic pulmonary venoconstriction could explain certain forms of pulmonary edema, such as high altitude pulmonary edema, which is initially caused by an increase in pulmonary capillary pressure [7].

\section{The cellular mechanism of HPV}

Numerous studies have been devoted to the mechanism responsible for relating pulmonary vascular tone to changes in $\mathrm{PO}_{2}$. A series of vasoconstrictors including histamine, serotonin, angiotensin, prostaglandins, and leukotrienes have been excluded as potential mediators. The hypothesis that hypoxia initiates pulmonary vasoconstriction by a reduction of high-energy phosphates has not been confirmed. Other hypotheses, including cytochrome $\mathrm{P} 450$ as a sensor of the decrease in $\mathrm{PO}_{2}$ triggering pulmonary vasoconstriction, or HPV as a result of the inhibition of endogenous vasodilator mediators such as NO, have also not been confirmed [5].

It has recently been shown that pulmonary vascular smooth muscle cells and type I cells of the carotid body share the ability to sense changes in $\mathrm{PO}_{2}$. Hypoxia has been demonstrated in both cells to inhibit outward potassium current, causing membrane depolarization and calcium entry through the voltage-dependent calcium channels [5]. There is evidence in both cells to suggest that changes in the redox status of the oxygen-sensitive potassium channels may control the current flow, so that the channel is open when oxidized and closed when reduced [5]. Two such oxygen-sensitive potassium channels, $\mathrm{Kv}_{2.1}$ and $\mathrm{Kv}_{1.5}$, have been identified in rat pulmonary arteries [8]. In systemic arteries, hypoxia causes an inward current through ATP-dependent potassium channels and vasodilatation. Profound hypoxia also dilates pulmonary arteries by the same mechanism.

\section{Stimulus-response curves for HPV}

The relationship between $\mathrm{FIO}_{2}$ or $\mathrm{PAO}_{2}$ and HPV, expressed as a change in Ppa at a given flow or as an amount of flow diversion at a given $\mathrm{Ppa}$, has been generally found in experimental animal preparations to be either sigmoid [9] or linear [10] in shape, with a continued constriction as long as $\mathrm{FiO}_{2}$ or $\mathrm{PAO}_{2}$ was decreased. However, in isolated in vivo pig lungs at constant flow, in which particular attention was paid to reaching a steady state before each measurement, the $\mathrm{Ppa}-\mathrm{PAO}_{2}$ curve 
was shown to be biphasic, with a maximum at $\mathrm{PAO}_{2}$ between 30 and 60 Torr, and a down sloping portion, or hypoxic pulmonary vasodilation, at lower $\mathrm{PAO}_{2}$ [11]. In dogs, a species with a pulmonary vasoreactivity to hypoxia comparable with that of man [4], the relationship between $\mathrm{FIO}_{2}$ progressively decreased from 1 to 0.06 , and $\mathrm{Ppa}$ measured at a constant $Q$ has also been shown to be biphasic, with a down sloping portion at a $\mathrm{FIO}_{2}$ lower than 0.1 , corresponding to a $\mathrm{PaO}_{2}$ of 36-38 Torr [12]. Evidence of hypoxic pulmonary vasodilation in man was obtained during Operation Everest II [13], in which normal subjects were decompressed in a hypobaric chamber for 40 days to an atmospheric pressure $(\mathrm{Pb})$ equivalent to the summit of Mount Everest. The subjects presented an average Ppa of $34 \mathrm{mmHg}$ at rest and of $54 \mathrm{mmHg}$ at exercise at a $\mathrm{Pb}$ of 282 Torr (7620 m; resting $\mathrm{PaO}_{2}, 37$ Torr), that decreased to 33 and $48 \mathrm{mmHg}$, respectively, at a $\mathrm{Pb}$ of 240 Torr (8840 m; resting $\mathrm{PaO}_{2}, 30$ Torr) [13].

\section{The efficiency of HPV}

Grant et al [10] used the equations of control theory and the linear relationships between lobar blood flow and $\mathrm{PAO}_{2}$ found in the Coatimundi, an animal with a strong hypoxic pressor response, to calculate the efficiency of $\mathrm{HPV}$ as a mechanism to stabilize $\mathrm{PAO}_{2}$. They found a gain due to feedback (Gfb) of a maximum of 0.9 at a $\mathrm{PAO}_{2}$ between 60 and 80 Torr, rapidly falling off outside these values. A Gfb of 0.9 represents an active correction of $47 \%$ of the decrease in $\mathrm{PAO}_{2}$ that would occur in a passive system without HPV. Mélot et al [14] used the same equations and linear relationships between compartmental blood flow and $\mathrm{PAO}_{2}$ derived from inert gas elimination data obtained in healthy volunteers, and found a maximum Gfb of 0.63 at a $\mathrm{PAO}_{2}$ of 60 Torr, also rapidly falling off at lower and at higher $\mathrm{PAO}_{2}$. A Gfb of 0.63 represents an active correction by $39 \%$ of a decrease in $\mathrm{PAO}_{2}$ that would occur in a passive system without HPV. These studies suggested that the hypoxic pressor response is only a moderately efficient feedback mechanism, acting essentially at $\mathrm{PAO}_{2}$ values higher than known to occur in severe lung diseases. The studies even supported the speculation that HPV would be merely some fetal remnant and not useful in extra-uterine life. However, more recent evaluations of the efficiency of hypoxic pressor response using a multicompartment lung model [15] fed by real data biphasic stimulus-response curves [16] have led to the conclusions that HPV is really effective in improving gas exchange in severe respiratory insufficiency.

A quantification of the efficiency of HPV in terms of correction of arterial hypoxemia in either decompensated chronic obstructive pulmonary disease (COPD) or acute respiratory distress syndrome (ARDS) is presented in Figure 1. Patients with COPD are hypoxemic because of increased dispersion of the distributions of perfusion and ventilation, with increased perfusion to lung units with a lower than
Figure 1

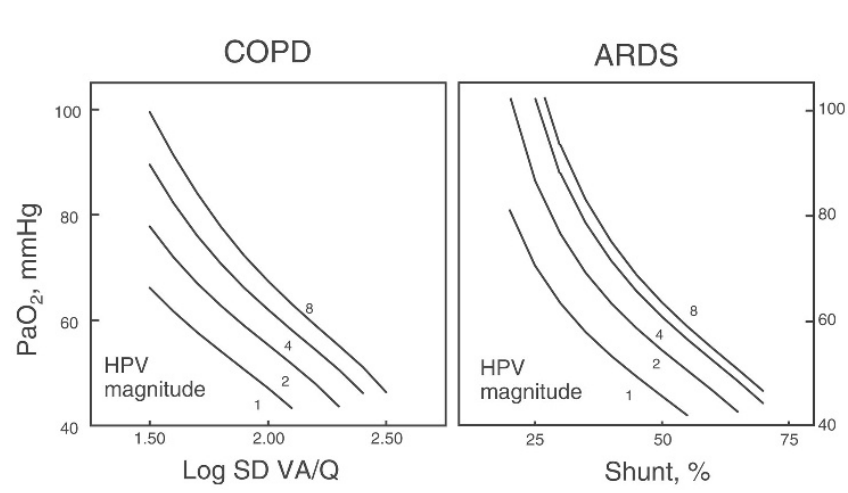

Effects of HPV in COPD, a lung disease characterized by VA/O mismatching, and in ARDS, a disease characterized by an increased shunt. LogSD VA/Q, logarithmic standard deviation of lognormal VA/Q distribution. $\mathrm{FIO}_{2}$ was set at 0.3 in COPD and 0.4 in ARDS.

(Reproduced with permission from [16].)

normal $V A / Q$ value $[17,18]$. Altered pulmonary gas exchange in these patients can thus be quantified by the logarithm of the standard deviation of VA/Q dispersion, whereas the strength of HPV can be expressed as Ppa in hypoxia divided by Ppa in hyperoxia at constant flow [16]. The magnitude of HPV ranges normally from 1 to 4 in the canine and in the human species. It can be seen that, in COPD, $\mathrm{PaO}_{2}$ may increase by up to $20 \mathrm{mmHg}$ through the effects of vigorous HPV. This is indeed the range of $\mathrm{PaO}_{2}$ observed in these patients from enhanced HPV by almitrine [17] to inhibited HPV by nifedipine [18].

Patients with ARDS are hypoxemic mainly because of an increased shunt $[19,20]$. Altered gas exchange in these patients can thus be quantified by intrapulmonary shunt, expressed in percent of cardiac output. Figure 1 shows that, in ARDS, $\mathrm{PaO}_{2}$ may increase by as much as $20 \mathrm{mmHg}$ owing to vigorous HPV. This is in keeping with the magnitude of decreases in arterial oxygenation observed in patients with ARDS due to inhibition of HPV by diltiazem [19] or prostaglandin $E_{1}$ [20].

Recent positron emission tomography can studies in experimental oleic acid lung injury clearly show an increased perfusion in the most dependent lung regions, together with an important decrease in $\mathrm{PaO}_{2}$ when $\mathrm{HPV}$ is ablated by a minute amount of endotoxin [21]. The results of a typical experiment are shown in Figure 2. The deterioration in $\mathrm{PaO}_{2}$ by the inhibition of HPV in this experimental ARDS model conforms to multicompartment lung HPV model predictions [22].

\section{HPV in acute lung injury}

HPV has been reported inhibited in some models of acute lung injury. As already mentioned, HPV is preserved in 
Figure 2
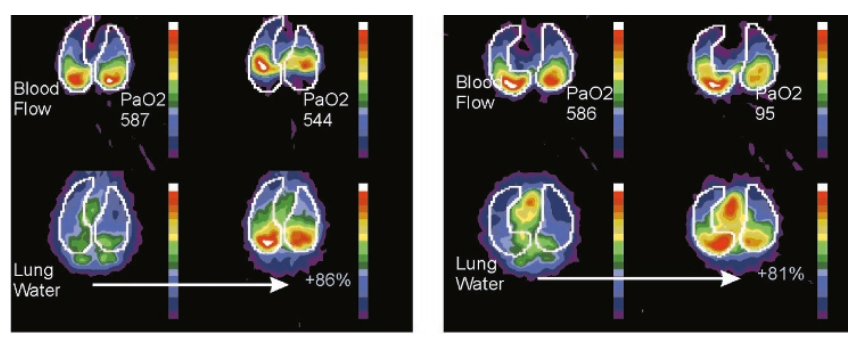

Positron emission tomography measurements of regional blood flow and lung water in a supine dog ventilated with pure oxygen, before and after induction of oleic acid lung injury, with intact (left) or ablated (right) hypoxic pulmonary vasoconstriction. Lung injury is associated with a significant increase in lung water. Pulmonary blood flow is redistributed upwards by hypoxic pulmonary vasoconstriction, and this is associated with preserved arterial $\mathrm{PO}_{2}$. (Reproduced with permission from [21].)

oleic acid lung injury but can be ablated by minute amounts of endotoxin. That HPV is still operative in most patients with ARDS is indicated by the clinical observation of acute pulmonary hypertension at accidental interruption of artificial ventilation, and by the hypoxemic effects of intravenously administered vasodilator drugs that inhibit HPV $[19,20]$. The persistence of active pulmonary vascular tone is also shown by the effects of inhaled vasodilators such as $\mathrm{NO}$ [23] or prostacyclin [24], which increase $\mathrm{PaO}_{2}$ because of an improved VA/Q matching by a redistribution of perfusion to the lung regions with the highest VA/O value. These observations have led to attempts of correction of hypoxemia in patients with ARDS by a combination of inhaled vasodilators to vasodilate the most healthy lung regions, and by intravenous constrictors to vasoconstrict the most diseased lung regions $[25,26]$. However, until now there has been no demonstration of clinical benefit of improved gas exchange by pharmacological manipulation of HPV. This is probably due to the fact that an increase in arterial oxygenation by pharmacological enhancement of HPV would be of clinical relevance only in situations of lifethreatening hypoxemia. Most patients with ARDS do not die from asphyxia, but from multiple organ failure.

\section{Effects of anesthesia}

Spinal anesthesia has been shown to enhance HPV [27], but the clinical relevance of this observation is uncertain. Intravenous anesthetics have generally been found to be without any effect on HPV [28]. Inhaled anesthetics have been reported to inhibit HPV in a variety of in vitro experimental preparations [28]. For example, in isolated rat lungs in vitro, halothane, enflurane, and isoflurane inhibit the hypoxic pressor response to the same extent at identical concentrations expressed as minimal alveolar concentrations units, with a $50 \%$ effective dose of approximately 0.6 [29]. In more intact animal preparations and in patients, however, higher concentrations than minimal alveolar concentration 1 are needed to inhibit HPV [30].

\section{Conclusions}

Pharmacological manipulations of HPV are feasible, and are associated with important changes in pulmonary gas exchange and in arterial oxygenation. The clinical relevance of this fascinating physiological phenomenon remains to be properly assessed.

\section{References}

1. von Euler US, Liljestrand G: Observations on the pulmonary arterial blood pressure in the cat. Acta Physiol Scand 1946, 12:301-320.

2. Brimioulle $S$, Lejeune $P$, Vachiéry $\mathrm{J}$, Leeman $M$, Mélot $C$, Naeije $\mathrm{R}$ : Effects of acidosis and alkalosis on hypoxic pulmonary vasoconstriction in dogs. Am J Physiol 1990, 258 (Heart Circ Physio/ 27):H347-H353.

3. Fishman AP: Pulmonary circulation. In: Handbook of Physiology. The Respiratory System. Circulation and Nonrespiratory Functions, section 3, vol 1, chapter 3. Bethesda, MD: American Physiological Society, 1985: 93-166.

4. Grover RF, Wagner WW, McMurtry IF, Reeves JT: Pulmonary circulation. In: Handbook of Physiology. Section 2: The Cardiovascular System. Volume III: Peripheral Circulation and Organ Blood Flow, part 1. Bethesda, MD: American Physiological Society, 1985: 103-136.

5. Weir EK, Archer SL: The mechanism of acute hypoxic pulmonary vasoconstriction: the tale of two channels. FASEB J 1995, 9:183-189.

6. Hillier SC, Graham JA, Hanger CC, Godbey P, Glenny RW, Wagner WW: Hypoxic vasoconstriction in pulmonary arterioles and venules. J Appl Physiol 1997, 82:1084-1090.

7. Maggiorini M, Mélot C, Pierre S, Pfeiffer F, Greve I, Sartori C, Lepori M, Hauser M, Scherrer U, Naeije R: High altitude pulmonary edema is initially caused by an increased capillary pressure. Circulation 2001, in press.

8. Archer SL, Souil E, Dinh-Xuan AT, Schremmer B, Mercier JC, Elyeagoubi A, Nguyen-Huu L, Reeve H, Hampl V: Molecular identification of the role of voltage-gated $\mathrm{K}^{+}$channels, $\mathrm{Kv} 1.5$ and Kv2.1, in hypoxic pulmonary vasoconstriction and control of resting membrane potential in rat pulmonary artery myocytes. J Clin Invest 1998, 101:2319-2330.

9. Barer GR, Howard P, Shaw JW: Stimulus-response curves for the pulmonary vascular bed to hypoxia and hypercapnia. J Physiol 1970, 21:139-155.

10. Grant BJB, Davies EE, Jones HA, Hughes JMB: Local regulation of pulmonary blood flow and ventilation-perfusion ratios in the coatimundi. J Appl Physiol 1976, 40:216-228.

11. Sylvester JT, Harabin AL, Peake MD, Frank RS: Vasodilator and constrictor responses to hypoxia in isolated pig lungs. $J$ Appl Physiol 1980, 49:820-825.

12. Brimioulle $S$, Lejeune $P$, Vachiéry JL, Delcroix $M$, Hallemans $R$, Leeman M, Naeije R: The stimulus-response curve of hypoxic pulmonary vasoconstriction in intact dogs: effects of ASA. J Appl Physiol 1994, 77:476-480.

13. Groves BM, Reeves JT, Sutton JR, Wagner PD, Cymerman A, Malconian MK, Rock PB, Young PM, Houston CS: Operation Everest II: elevated high-altitude pulmonary resistance unresponsive to oxygen. J App/ Physiol 1987, 63:521-530.

14. Mélot $C$, Naeije R, Hallemans R, Lejeune P, Mols P: Hypoxic pulmonary vasoconstriction and pulmonary gas exchange in normal man. Respir Physiol 1987, 68:11-27.

15. Marshall BE, Marshall C: A model for hypoxic constriction of the pulmonary circulation. J App/ Physiol 1988, 64:68-77.

16. Brimioulle $S$, Lejeune P, Naeije R: Effects of hypoxic pulmonary vasoconstriction on gas exchange. J Appl Physiol 1996, 81: 1535-1543.

17. Mélot $C$, Naeije R, Rothschild T, Mertens $P$, Mols $P$, Hallemans R: Improvement in ventilation-perfusion matching by almitrine in chronic obstructive pulmonary disease. Chest 1983, 83:528533. 
18. Mélot $C$, Hallemans R, Mols $P$, Lejeune $P$, Naeije R: Deleterious effects of nifedipine on pulmonary gas exchange in chronic obstructive pulmonary disease. Am Rev Respir Dis 1984, 130: 612-616.

19. Mélot C, Naeije R, Mols P, Hallemans R, Lejeune P, Jaspar N: Pulmonary vascular tone improves gas exchange in the adult respiratory distress syndrome. Am Rev Respir Dis 1987, 136: $1232-1236$.

20. Mélot $C$, Lejeune $P$, Leeman $M$, Moraine JJ, Naeije R: Prostaglandin E1 in the adult respiratory distress syndrome: benefit for pulmonary hypertension and cost for pulmonary gas exchange. Am Rev Respir Dis 1989, 139:106-110.

21. Gust R, Kozlowski J, Stephenson AH, Schuster DP: Synergistic hemodynamic effects of low-dose endotoxin in acute lung injury. Am J Respir Crit Care Med 1998, 157:1919-1926.

22. Naeije R, Brimioulle S, Gust R, Kozlowski JK, Julien V, Schuster DP: The importance of hypoxic pulmonary vasoconstriction in maintaining arterial oxygenation in acute lung injury. Eur Respir J 2000, 16:365S.

23. Rossaint R, Falke KJ, Lopez F, Slama K, Pison U, Zapol WM: Inhaled nitric oxide for the adult respiratory distress syndrome. N Engl J Med 1993, 328:399-405.

24. Swissler B, Kemming G, Habler O, Kleen M, Merkel M, Haller M, Briegel J, Welte M, Peter K: Inhaled prostacyclin (PGI2) versus inhaled nitric oxide in adult respiratory distress syndrome. Am $J$ Respir Crit Care Med 1996, 154:1671-1677.

25. Gallart L, Lu Q, Puybasset L, Umamaheswara Rao GS, Coriat P, Rouby JJ: Intravenous almitrine combined with inhaled nitric oxide for acute respiratory distress syndrome. The NO Almitrine Study Group. Am J Respir Crit Care Med 1998, 158: 1770-1777.

26. Papazian L, Roch A, Bregeon F, Thirion X, Gaillat F, Saux P, Fulachier V, Jammes Y, Auffray JP: Inhaled nitric oxide and vasoconstrictors in acute respiratory distress syndrome. $\mathrm{Am} \mathrm{J}$ Respir Crit Care Med 1999, 160:473-479

27. Brimioulle $S$, Vachiéry JL, Brichant JF, Delcroix M, Lejeune $P$, Naeije R: Effects of epidural vs adrenergic receptors blockade on hypoxic pulmonary vasoconstriction in intact dogs. Cardiovasc Res 1997, 34:384-392.

28. Eisenkraft JB: Effects of anaesthetics on the pulmonary circulation. Br J Anaesth 1990, 65:63-78.

29. Marshall C, Lindgren L, Marshall BE: Effects of halothane, enflurane and isoflurane on hypoxic pulmonary vasoconstriction in rat lungs in vivo. Anesthesiology 1984, 60:304-308.

30. Ewalenko P, Stefanidis C, Holoye A, Brimioulle S, Naeije R: Pulmonary vascular impedance versus resistance in hyperoxic and hypoxic dogs: effects of propofol and isoflurane. J Appl Physiol 1993, 74:2188-2193. 